\title{
Cardiorenal effects of newer antidiabetic agents
}

\author{
Athanasia K. Papazafiropoulou, Elias Georgopoulos, Stavros Antonopoulos
}

1st Department of Internal Medicine and Diabetes Center, Tzaneio General Hospital of Piraeus, Greece

\begin{abstract}
Chronic kidney disease is a major problem of public health and is associated with increased cardiovascular mortality and morbidity. Its treatment includes multifactorial intervention: optimal blood pressure and intensive glycaemic control. There are many studies - clinical and experimental - demonstrating that classic and newer antidiabetic agents delay the progression of diabetic nephropathy. Glucagon-like-peptide-1 (GLP1) receptor agonists and sodium-glucose co-transporters-2 (SGLT-2) inhibitors have renoprotective action. Furthermore, these antidiabetic agents have beneficial effects to the cardiovascular system, including weight loss and blood pressure reduction. Large, randomized, placebo-controlled outcome trials have showed that SGLT-2 inhibitors and GLP-1 receptor agonists are able to reduce cardiovascular events. Therefore, the present review aims to summarize the existing data regarding the effect of newer antidiabetic agents on kidney function and cardiovascular system.
\end{abstract}

KEY WORDS: Diabetes mellitus, diabetic nephropathy, cardiovascular disease, glucagon-like peptide-1 receptor agonists, sodium-glucose co-transporter-2 inhibitors, heart failure

\section{INTRODUCTION}

According to the World Health Organization in 2014 $8,5 \%$ of the adults, globally, had diabetes mellitus while this number will be doubled in 2030. ${ }^{1}$ It is well established that diabetes is an independent cardiovascular (CV) risk factor; patients with diabetes have 2-fold higher risk for death compared to patients without diabetes and similar risk compared to patients with previous myocardial infarction. ${ }^{2,3}$ Furthermore, diabetes is the leading cause of endstage renal disease (ESRD) while one-third of patients with diabetes will develop chronic kidney disease (CKD) during

Corresponding author:

Athanasia K. Papazafiropoulou, MD, MSc, PhD

1st Department of Internal Medicine and Diabetes Center,

Tzaneio General Hospital of Piraeus,

1 Zanni and Afentouli Street, Piraeus 18536, Greece

Tel.: +306979969483

E-mail: pathan@ath.forthnet.gr their life. ${ }^{4}$ CKD is a major risk factor for the development of CV mortality and morbidity. ${ }^{5}$ The first manifestation of CKD in patients with diabetes is microalbuminuria. The prevalence of microalbuminuria is $25 \%$ after 10 years of the clinical onset of diabetes while the annual rate of

ABBREVIATIONS: ASCVD: atherosclerotic cardiovascular disease, ATP: adenosine triphosphate, Cl:confidence interval, CKD: chronic kidney disease, CKD-EPI: Chronic Kidney Disease Epidemiology Collaboration, CV:cardiovascular, DAPA-CKD:Dapagliflozin And Prevention of Adverse outcomes in Chronic Kidney Disease, DCCT: Diabetes Control and Complications Trial, DDP-4i: dipeptidylpeptidase-inhibitors, DN: diabetic nephropathy, eGFR: estimated glomerular filtration rate, ESRD: end-stage renal disease, FDA: Food and Drug Administration, GLP-1: glucagon-like-peptide-1, HF: heart failure, HR: hazard ratio, MACE: major adverse cardiac events, MI: myocardial infarction, RAS: renin-angiotensin blockade, SGLT-2: sodium-glucose co-transporters-2, T2D: type 2 diabetes, UACR: albumin to creatinine ratio

Submission: 17.03.2020, Acceptance: 04.05.2020 
progression to macroalbuminuria is $3 \% .^{6}$

In 2008, the Food and Drug Administration (FDA), required for all novel antidiabetic agents to have proven the non-inferiority of the major CV events before licensing. ${ }^{7}$ The first trials with dipeptidyl-peptidase-inhibitors (DDP-4i) proved non-inferiority and the other studies with sodium-glucose transporters 2 inhibitors (SGLT-2i) (-10 $^{8}$ and glucagon-like peptide (GLP-1) receptor agonists ${ }^{11,12}$ proven superiority. Secondary analyses proved that these antidiabetic agents have renoprotective action. Empagliflozin in EMPA-REG OUTCOME trial reduced the primary 3-point nonfatal myocardial infarction, nonfatal stroke, and CV death (major adverse cardiac events, MACE) outcome significantly, and also reduced CV death, overall mortality, and hospitalization for heart failure (HF) ${ }^{7,8}$. In the CANVAS trial $^{9}$, patients treated with canagliflozin had a lower risk of cardiovascular events than those who received placebo, a result driven by the reduction of the hospitalization for HF. In the DECLARE TIMI 58 trial $^{10}$, treatment with dapagliflozin did not result in a higher or lower rate of MACE than placebo but did result in a lower rate of cardiovascular death or hospitalization for HF, a finding that reflects a lower rate of hospitalization for HF. The above-mentioned trials have changed the current guidelines and the philosophy of the management of patients with DM. Therefore, the aim of the present review is to summarize the existing literature data, regarding the renal and CV effects or the novel antidiabetic agents, SGLT-2i and GLP-1 agonists.

\section{SGLT-2I, GLP-1 RECEPTOR AGONISTS AND RENAL EFFECTS}

The pathogenesis of the development of diabetic nephropathy (DN) is not completely understood. The major pathophysiological mechanisms are; oxidative stress, inflammatory injury of tubular cells, tubulointerstitial fibrosis, podocytes loss, and endothelial dysfunction. ${ }^{13}$ Clinical trials have demonstrated that intensive control of glycaemia and blood pressure delay the progression of DN. ${ }^{14-17}$ On the other hand, intensive glycaemic control leads to reduction of the onset as well as the progression of albuminuria in patients with type 1 and type 2 diabetes (T2D). ${ }^{18-21}$

The Diabetes Control and Complications Trial (DCCT), in patients with type 1 diabetes, demonstrated that intensive glycaemic control reduces the progression of DN. ${ }^{20}$ More intensive blood glucose control resulted in both a $33 \%$ reduction in relative risk of development of microalbuminuria or clinical grade proteinuria at 12 years. ${ }^{21}$ Furthermore, in the ADVANCE Study, intensive glycaemic control reduced albuminuria and the need for dialysis ${ }^{22}$ and, in accordance, in the ACCORD Study, intensive gly- caemic control reduced albuminuria. ${ }^{23}$ In the ADVANCE Study reduction of blood pressure and intensive glucose control leaded to the reduction of all-cause mortality and major renal events ( $21 \%$ relative risk reduction of new or worsening nephropathy). ${ }^{22}$ Despite the above beneficial results, the VADT Study showed that intensive glycaemic control did not improve either nephropathy or retinopathy. ${ }^{24}$

\section{GLP-1 receptor agonists}

The favorable effect of GLP-1 receptor agonists on renal function (Table 1), except for glycaemic control, is mediated through the multifactorial management of the blood pressure, dyslipidemia and body weight. Carefully designed studies in people with T2D using inulin and $\mathrm{p}$ aminohippuric acid infusion techniques measured changes in GFR and renal plasma flow failed to demonstrate that GLP-1 receptor agonists reduce glomerular pressure or have other beneficial renal hemodynamic actions. ${ }^{25,26}$ Additionally, GLP-1 receptor agonists reduce proteinuria via reduction of the endothelial injury and oxidative stress. ${ }^{27,28}$ However, the main renoprotective effect of GLP-1 receptor agonists is their favorable action in distal convoluted tubule and promote natriuresis, via reduction of sodium reabsorbtion, in distal convoluted tubule..$^{29,30}$ GLP-1 receptor agonists restore the tubule-glomerular feedback, as a result of vasoconstriction of afferent arteriole, promoting the reduction of intra-glomerular pressure. ${ }^{29}$ Von Sholten et al., showed that liraglutide, in $1.8 \mathrm{mg} /$ day, reduced progressively albumin to creatinine ratio, estimated glomerular filtration rate (eGFR) and fractional albumin excretion. ${ }^{31}$ Finally, it seems that the main renoprotective action of GLP-1 receptor agonists is mediated by the vasoconstriction of the afferent arteriole and the reduction of intra-glomerular pressure. ${ }^{32}$

In the LEADER trial, liraglutide therapy reduced significantly the composite end point of macroalbuminuria, ESRD, or death from renal disease versus placebo [Hazard ratio (HR):0.78, 95\% confidence interval (Cl): 0.67-0.92]..$^{33}$ The above result is mainly due to the reduction of newonset macroalbuminuria, and not from the reduction of the others components (HR:0.74, 95\% Cl: 0.60-0.91). It is noteworthy that the reduction of the composite end point was similar in the sub-group of patients with eGFR $<60 \mathrm{ml} /$ $\mathrm{min} / 1.73 \mathrm{~m}^{2}$. The urine albumin to creatinine ratio (UACR) was reduced by $17 \%$ in the liraglutide group independently of eGFR. The incidence of microalbuminuria was lower significantly in liraglutide group (HR:0,87, 95\% Cl: $0,83-0,93)$, while there were no differences in renal adverse events among the two study groups..$^{31}$ In smaller studies, liraglutide reduced albuminuria about $30 \%$ independently 
TABLE 1. Cardiovascular and renal outcomes of GLP-1 receptor agonists

\begin{tabular}{|c|c|c|c|c|c|c|}
\hline & ELIXA & LEADER & EXSCEL & SUSTAIN 6 & REWIND & HARMONY \\
\hline $\begin{array}{l}\text { Patients with } \\
\text { established cv disease }\end{array}$ & $100 \%$ & $81 \%$ & $73 \%$ & $83 \%$ & $31.5 \%$ & $100 \%$ \\
\hline \multicolumn{7}{|l|}{ CV outcomes } \\
\hline MACE-3 & - & $\begin{array}{c}0.87 \\
(0.78-0.97)\end{array}$ & $\begin{array}{c}0.91 \\
(0.83-1.00)\end{array}$ & $\begin{array}{c}0.74 \\
(0.58-0.95)\end{array}$ & $\begin{array}{c}0.88 \\
(0.79-0.99)\end{array}$ & $\begin{array}{c}0.78 \\
(0.68-0.90)\end{array}$ \\
\hline CV death & $\begin{array}{c}0.98 \\
(0.78-1.22)\end{array}$ & $\begin{array}{c}0.78 \\
(0.66-0.93)\end{array}$ & $\begin{array}{c}0.88 \\
(0.76-1.02)\end{array}$ & $\begin{array}{c}0.98 \\
(0.65-1.48)\end{array}$ & $\begin{array}{c}0.91 \\
(0.78-1.06)\end{array}$ & $\begin{array}{c}0.93 \\
(0.73-1.19)\end{array}$ \\
\hline Non-fatal MI & - & $\begin{array}{c}0.88 \\
(0.75-1.03)\end{array}$ & $\begin{array}{c}0.97 \\
(0.8-1.10)\end{array}$ & $\begin{array}{c}0.74 \\
(0.51-1.08)\end{array}$ & $\begin{array}{c}0.96 \\
(0.79-1.16)\end{array}$ & $\begin{array}{c}0.75 \\
(0.61-0.90)\end{array}$ \\
\hline Non-fatal stroke & - & $\begin{array}{c}0.89 \\
(0.72-1.11)\end{array}$ & $\begin{array}{c}0.85 \\
(0.70-1.03)\end{array}$ & $\begin{array}{c}0.61 \\
(0.38-0.99)\end{array}$ & $\begin{array}{c}0.76 \\
(0.61-0.95)\end{array}$ & $\begin{array}{c}0.86 \\
(0.66-1.14)\end{array}$ \\
\hline Mortality & $\begin{array}{c}0.94 \\
(0.78-1.13)\end{array}$ & $\begin{array}{c}0.85 \\
(0.74-0.97)\end{array}$ & $\begin{array}{c}0.86 \\
(0.77-0.97)\end{array}$ & $\begin{array}{c}1.05 \\
(0.74-1.50)\end{array}$ & $\begin{array}{c}0.90 \\
(0.80-1.01)\end{array}$ & $\begin{array}{c}0.95 \\
(0.79-1.16)\end{array}$ \\
\hline HF hospitalization & $\begin{array}{c}0.96 \\
(0.75-1.23)\end{array}$ & $\begin{array}{c}0.87 \\
(0.73-1.05)\end{array}$ & $\begin{array}{c}0.94 \\
(0.78-1.13)\end{array}$ & $\begin{array}{c}1.11 \\
(0.77-1.61)\end{array}$ & $\begin{array}{c}0.93 \\
(0.77-1.12)\end{array}$ & - \\
\hline \multicolumn{7}{|l|}{ Renal outcomes } \\
\hline $\begin{array}{l}\text { Composite renal } \\
\text { outcome }\end{array}$ & - & $\begin{array}{c}0.78 \\
(0.67-0.92)\end{array}$ & $\begin{array}{c}0.88 \\
(0.74-1.05)\end{array}$ & $\begin{array}{c}0.64 \\
(0.46-0.88)\end{array}$ & $\begin{array}{c}0.85 \\
(0.77-0.93)\end{array}$ & - \\
\hline
\end{tabular}

*Data are presented as hazard ratio, $95 \%$ confidence intervals

Abbreviations: CV: cardiovascular, MACE: major adverse cardiovascular events, MI: myocardial infraction, HF: heart failure

of eGFR.34,35 In the SCALE Study, liraglutide $3 \mathrm{mg} /$ day (dose for pharmaceutical treatment for obesity) showed an $18 \%$ reduction of albuminuria. ${ }^{36}$

The SUSTAIN- 6 trial evaluated the efficacy of semaglutide on kidney function with a secondary renal composite end point the onset of microalbuminuria, doubling of serum creatinine, creatinine clearance $>45 \mathrm{ml} / \mathrm{min}$ or need for haemodialysis. This point was significantly lower in semaglutide group than placebo (HR:0.64, 95\% Cl: 0.46$0.88)$, driven mostly from the reduction of new-onset macroalbuminuria (2.5 \% vs $4.9 \%){ }^{12}$

In the ELIXA trial, lixisenatide was associated with a lower increase in UACR compared the placebo (24\% vs. 34\%, $\mathrm{p}=0.004)$.28 In EXSCEL trial, exenatide LAR was associated with a reduction of the renal composite point $(40 \%$ reduction in eGFR, need for renal replacement therapy, renal death and new-onset macroalbuminuria) compared with placebo (HR:0.85, 95\% Cl: 0.73-0.98). This significant reduction of the composite point came from the reduction of new-onset macroalbuminuria. ${ }^{37}$ The only finding that we have from the HARMONY trial, with albiglutide, is that there was nodifference in eGFR levels between the two study groups since the trial was early terminated and no further analysis has been published regarding renal outcomes. ${ }^{38}$ In accordance, in larger clinical trials no clinically relevant effects on eGFR deterioration or slopes were observed over the long term, except for a modest eGFR preservation effect in the 30 to $60 \mathrm{~mL} / \mathrm{min} / 1.73 \mathrm{~m} 2$ subgroup in LEADER and a 1 and $2 \mathrm{~mL} / \mathrm{min} / \mathrm{y}$ preservation of eGFR in AWARD-7 at 52 weeks. $35,39,40$

Finally, in the REWIND trial, dulaglutide was associated with a significant reduction of renal composite of microvascular outcome (new-onset macroalbuminuria, sustained decline in eGFR of $30 \%$ or more from baseline, chronic renal replacement therapy) compared with placebo (HR:0.85, 95\% Cl: 0.77-0.93, $p=0.0004)$. The above reduction was driven by the reduction of new-onset macroalbuminuria (HR:0.77, 95\% Cl: 0.68-0.87, p<0.0001)..$^{41}$

The above findings of landmark CV trials clearly demonstrate that GLP-1 receptor agonists have renoprotective action clinical reflecting to the preservation of eGFR.

\section{SGLT-2i}

DN is characterized from hyperfiltration and increased intraglomerular pressure promoting thus the excretion of albumin. In patients with T2D, as a result of increased reabsorption of sodium and chloride in the proximal tubule, delivery to the macula densa is decreased, leadingto lower solute reabsorption. This is the main action of the nephroprotection caused by SGLT- $2 i{ }^{42-45}$ SGLT-2 $i$ inhibit the reabsorbtion of sodium and glucose in proximal convoluted tubule, as a result of the sodium senses the 
macula densa, decreasing the tubule-glomerular feedback promoting the vasoconstriction of afferent arteriole and, therefore, the intraglomerular pressure is reduced. ${ }^{46,47}$ There are several other possible pathogenetic mechanisms explaining the nephroprotective action of SGLT-2i, including their effect on blood pressure, fat mass, and uric acid, the reduction of kidney hypoxia, and thus the reduction of energy requirements.48 finally, experimental data suggest that SGLT-2i have anti-fibrotic, anti-inflammatory and antioxidant actions. ${ }^{49-51}$ An animal study showed that SGLT-2i improve histological lesions (interstitial fibrosis, glomerular enlargement, mesangial matrix accumulation), a finding associated with the reduction of progression of diabetic nephropathy. ${ }^{52}$ In a human study, empagliflozin reversed the glomerular hyperfiltration by modulating the tone of afferent arteriole. In hyperfiltrating patients, treatment with empagliflozin for 8 weeks resulted in reduction of GFR from $172 \pm 23$ to $139 \pm 25 \mathrm{~mL} / \mathrm{min} / 1.73$ $\mathrm{m}^{2}(\mathrm{P}<0.01)$. This was associated by a significant increase in renal vascular resistance, suggesting that this was due to decreased afferent arteriole vasodilation. ${ }^{53}$

The EMPAREG-OUTCOME and CANVAS trials have supported the renoprotective action of SGLT-2i expressed in terms of reduction of urine albumin excretion (Table 2). ${ }^{12,13}$ In the EMPAREG OUTCOME trial ${ }^{8}$, empagliflozin reduced the composite end point of progression of macroalbuminuria, death from renal disease or renal replacement therapy, and doubling of serum creatinine significantly (HR:0.61, 95\% Cl:
0.73-0.90). The renal analysis of the EMPAREG-OUTCOME trial examined further the effect of empagliflozin on eGFR using the Chronic Kidney Disease Epidemiology Collaboration (CKD-EPI) formula. observed A decrease of eGFR compared to placebo was observed with empagliflozin 10 and 25 mg during the firtst month of the trial, while . From week 4 to the end of the study, eGFR was stabilized in both groups, while after the cessation of the study, eGFR increased in both empagliflozin groups compared to placebo $(p<0.001)$. In a post-hoc analysis, empagliflozin reduced the composite point of renal replacement therapy or renal death and doubling serum creatinine significantly (HR:0.54, 95\% Cl: 0.40-0.75). Furthermore, empagliflozin reduced the progression of macroalbuminuria (HR:0.62, 95\% $\mathrm{Cl}$ : 0.54-0.72), doubling of serum creatinine (HR:0.56, 95\% $\mathrm{Cl}$ : 0.39-0.79) and initiation of renal replacement therapy (HR:0.45, 95\% Cl: 0.21-0.97). Finally, it must be mentioned that the EMPAREG OUTCOME trial did not enrolled patients with overt diabetic nephropathy. The study enrolled 5,201 patients with an eGFR>60 mL/min/ $1.73 \mathrm{~m}^{2}$ of which $64 \%$ had no albuminuria, $27 \%$ had microalbuminuria and $8.5 \%$ had macroalbuminuria. Only 1,819 patients with eGFR $<60$ $\mathrm{mL} / \mathrm{min} / 1.73 \mathrm{~m}^{2}$ (of which $47 \%$ had no albuminuria, $34 \%$ had microalbuminuria and $19 \%$ macroalbuminuria) were enrolled into the study. 8 This was the main limitation of this study regarding the results of renal composite point.

Similar results were observed in the CANVAS trial. ${ }^{9}$ In the CANVAS trial, whereas $20.1 \%$ of patients had eGFR

TABLE 2. Cardiovascular and renal outcomes of SGLT-2 inhibitors

\begin{tabular}{|c|c|c|c|}
\hline & EMPA-REG & CANVAS & DECLARE \\
\hline Patients with established cv disease & $99 \%$ & $65.6 \%$ & $40.6 \%$ \\
\hline \multicolumn{4}{|l|}{ CV outcomes } \\
\hline MACE-3 & $0.86(0.74-0.99)$ & $0.86(0.75-0.97)$ & $0.93(0.84-1.03)$ \\
\hline CV death & $0.62(0.49-0.77)$ & $0.87(0.72-1.06)$ & $0.98(0.82-1.17)$ \\
\hline Non-fatal MI & $0.87(0.70-1.09)$ & $0.85(0.69-1.05)$ & $0.89(0.77-1.01)$ \\
\hline Non-fatal stroke & $1.24(0.92-1.67)$ & $0.90(0.71-1.15)$ & $1.01(0.84-1.21)$ \\
\hline Mortality & $0.68(0.57-0.82)$ & $0.87(0.74-1.11)$ & $0.93(0.82-1.04)$ \\
\hline HF hospitalization & $0.65(0.50-0.85)$ & $0.67(0.47-0.77)$ & $0.73(0.61-0.88)$ \\
\hline \multicolumn{4}{|l|}{ Renal outcomes } \\
\hline Composite renal outcome & $0.61(0.53-0.70)$ & $0.64(0.46-0.88)$ & $0.53(0.43-0.66)$ \\
\hline Progression of albuminuria & - & $0.73(0.67-0.79)$ & \\
\hline $\begin{array}{l}40 \% \text { reduction in eGFR, renal- } \\
\text { replacement } \\
\text { therapy, or renal death }\end{array}$ & - & $0.60(0.47-0.77)$ & $0.53(0.43-0.66)$ \\
\hline
\end{tabular}

*Data are presented as hazard ratio, 95\% confidence intervals

Abbreviations: CV: cardiovascular, MACE: major adverse cardiovascular events, MI: myocardial infraction, HF: heart failure 
$<60 \mathrm{ml} / \mathrm{min} / 1.73 \mathrm{~m}^{2}$, canagliflozin significantly reduced the renal composite end point of $40 \%$ decline of eGFR, death of renal causes or need for renal replacement therapy (HR:0.60, 95\% Cl: 0.47-0.77). ${ }^{9}$ The reduction of renal composite end point was similar in patients with and without CKD among the 4 study groups (eGFR $>90 \mathrm{ml} / \mathrm{min} / 1.73$ $\mathrm{m}^{2}, 60-90,45-60,<45, \mathrm{p}$-heterogeneity $=0.28$ and $>0.5$ respectively). ${ }^{54}$ Doubling of serum creatinine was significantly reduced (HR: $0.50,95 \% \mathrm{Cl}: 0.30-0.84)$, but ESRD was not (HR: $0.77,95 \% \mathrm{Cl}$ : $0.30-1.97) .{ }^{55}$ Finally, the risk of new-onset microalbuminuria decreased by $20 \%$ (HR: 0.80 , 95\% Cl: $0.73-0.87$ ) and that of macroalbuminuria by $42 \%$ (HR: 0.58, 95\% Cl: 0.50-0.68) with canagliflozin.

In the DECLARE-TIMI 58 trial, dapagliflozin reduced significantly the secondary composite point of death from renal or CV causes, ESRD, $>40 \%$ decline of eGFR to eGFR $<60 \mathrm{ml} / \mathrm{min} / 1.73 \mathrm{~m}^{2}$ (HR:0.76, 95\% Cl: 0.67-0.87). However, subgroup analyses of albuminuria and composite renal point was not performed in DECLARE-TIMI 58 trial. $^{10}$

In a recent meta-analysis of these 3 trials (EMPAREGOUTCOME, CANVAS, DECLARE TIMI 58), SGLT-2i reduced the composite point of renal death, ESRD and worsening of renal function by $45 \%$ (HR:0.55, 95\% Cl: 0.48-0.64) in patients with and not established CV disease. ${ }^{56} \mathrm{It}$ is important to mention that the combination of renin-angiotensin blockade (RAS) with SGLT-2i have renoprotective action due to the greater reduction of intraglomerular pressure from this combination; RAS blockade leads to vasodilation of the efferent arteriole while SGLT-2 inhibition leads to vasoconstriction of the afferent arteriole, resulting to the reduction of intraglomerular pressure and hyperfiltration, and thus to reduction of albuminuria. . $^{57,58}$

A recent study supporting the above evidence is the CREDENCE trial. ${ }^{59}$ In this trial, all participants had CKD with eGFR 30-90 ml/min $/ 1.73 \mathrm{~m}^{2}$, ACR 300-5000 mg/g and were treated with RAS blockade. Canagliflozin reduced significantly the primary outcome of composite point of ESKD (dialysis, transplantation, sustained eGFR $<15 \mathrm{ml} /$ $\mathrm{min} / 1.73 \mathrm{~m}^{2}$ ), doubling serum creatinine, and death from renal or CV disease, compared to placebo (HR:0.70, 95\% CI $0.59-0.82, p=0.00001)$. Furthermore, canagliflozin reduced significantly the renal-specific composite point of ESKD, doubling serum creatinine, and death from renal causes (HR:0.66, 95\% Cl: 0.53-0.81, p<0.001) and ESKD (HR:0.68, 95\% Cl: 0.54-0.86, $\mathrm{p}=0.002$ ).

Recently, the early termination of Dapagliflozin And Prevention of Adverse outcomes in Chronic Kidney Disease (DAPA-CKD) trial was announced based on the observed efficacy of dapagliflozin. DAPA-CKD is an international, multi-center, randomized, double-blinded trial in 4,245 patients designed to evaluate the efficacy of dapagliflozin $10 \mathrm{mg}$, compared with placebo, in patients with CKD stages 2-4 and elevated urinary albumin excretion, with and without T2D. The primary endpoint of DAPA-CKD trial was a composite of worsening of renal function or death (defined as a composite endpoint of $\geq 50 \%$ sustained decline in eGFR, onset of end-stage kidney disease or CV or renal death) in patients with CKD irrespective of the presence of T2D. ${ }^{60}$

\section{SGLT-2I, GLP-1 RECEPTORS AGONISTS AND CV EFFECTS}

\section{GLP-1 receptor agonists}

It is well established that the CV benefits of GLP-1 receptors agonists, as it has been showed by their major $\mathrm{CV}$ trials, is independent of the observed reduction of $\mathrm{HbA} 1 \mathrm{c}$ (HbA1c difference $0.4 \%$ in LEADER trial ${ }^{11}, 0.8 \%$ in SUSTAIN-6 trial' ${ }^{12}, 0.6 \%$ in HARMONY OUTCOMES trial38 compared to placebo) (Table 1). Many pathogenetic mechanisms have been proposed in order to explain the observed cardioprotection of the GLP-1 receptor agonists. It is well documented that GLP-1 receptor agonists improve renal function, and established CV risk factors like weight and lipid profile. ${ }^{61,62}$ They reduce body weight and waist circumference as a result of reducing total fat rather than lean tissue mass. ${ }^{63,64}$ Their favorable effect of GLP-1 receptors agonists on weight is mediated by the reduction satiety, the appetite suppression and delaying gastric emptying. ${ }^{65-67}$

Some, but not all, GLP-1 receptor agonists have antihypertensive action; according to a recent meta-analysis liraglutide and albiglutide have antihypertensive action but not dulaglutide and exenatide.68 The proposed mechanism for the favorable effect of GLP-1 receptor agonists on blood pressure is mediated by the release of atrial natriuretic peptide leading to natriuresis, vasodilation and improved endothelial function. ${ }^{69-71}$ In addition, GLP-1 receptor agonist have direct action to the proximal renal tubule. ${ }^{72-74}$ Another pleiotropic effect of GLP-1 receptor agonists is their beneficial effect on lipid profile; the underlying mechanisms include reductions in post-prandial chylomicron synthesis and reduced triglyceride absorption, as well as increased postprandial insulin production and reduction in glucagon release leading to inhibition of adipose tissue lipolysis. ${ }^{68,75-78}$

It must be mentioned that, in contrast to SGLT-2i trials, hospitalization for HF was not improved with GLP-1 receptor agonists; liraglutide did not improve hospitalization for HF or functional status in patients with reduced left ventricular function. ${ }^{79}$ However, in a trial with GLP-1 receptor agonist, left ventricular function, functional status and quality of life in patients with severe HF was improved, a finding in both diabetic and non-diabetic patients. ${ }^{80}$ In 
patients with acute myocardial infarction (MI) and systolic dysfunction, GLP-1 receptor agonist therapy improved left ventricular function after primary angioplasty. ${ }^{81}$ The pathogenetic mechanisms for the beneficial action of GLP-1 receptor agonists include their effect on apoptosis of cardiomyocytes and cardiac fibrosis. ${ }^{82,83}$

The first study to examine the CV effects of GLP-1 receptor agonists was the ELIXA trial. In the ELIXA trial, 6,068 patients with T2D with either a MI or hospitalized for unstable angina in the preceding 180 days, were randomized to receive either lixisenatide 10-20 gr or placebo. ${ }^{30}$ The primary endpoint was a composite of CV death, MI, stroke or hospitalization for HF. After a median follow-up of 25 months, $13.4 \%$ patients receiving lixisenatide and $13.2 \%$ receiving placebo reached the primary endpoint (HR: $1.02,95 \% \mathrm{Cl}: 0.89-1.17)$. The trial showed the noninferiority of lixisenatide to placebo $(p<0.001)$ but failed to show superiority $(p=0.81)$. There was no difference between groups in any of the CV outcomes when considered individually, or in all-cause mortality. No significant interactions were observed for the primary endpoint and renal function and there were no differences to the risk of hospitalization for HF between the two groups.

In the LEADER trial, with liraglutide, 9,380 patients with $T 2 D$ and high $C V$ risk were randomized to receive either liraglutide or placebo. ${ }^{11}$ The primary endpoint was a composite of CV death, MI or stroke. After a median follow-up of 3.8 years, $13.0 \%$ patients on liraglutide and $14.9 \%$ patients on placebo reached the primary endpoint (HR: 0.87, 95\% Cl: 0.78-0.97; $\mathrm{p}<0.001$ for non-inferiority and $\mathrm{p}=0.01$ for superiority). All-cause mortality (HR: 0.85, 95\% Cl: 0.74-0.97) and CV death (HR: 0.78, 95\% Cl: 0.66-0.93) were lower with liraglutide. Rates of non-fatal $\mathrm{MI}$, non-fatal stroke and hospitalization for HF were nonsignificantly lower in the liraglutide group. Patients with CKD (eGFR<60 mL/min/1.73 m2) showed to have greater benefit (HR: 0.69, 95\% Cl: 0.57-0.85) than patients with eGFR >60 mL/min/1.73 m2 (HR: 0.94, 95\% Cl: 0.83-1.07) in the liraglutide arm.

In the SUSTAIN-6 trial, with the once-weekly GLP-1 receptor agonist semaglutide, 3,297 patients with T2D and established CV disease were randomized to once-weekly semaglutide ( 0.5 or $1.0 \mathrm{mg}$ ) or placebo for 104 weeks. ${ }^{12}$ The primary composite outcome included CV death, non-fatal MI or non-fatal stroke. The primary outcome occurred in $6.6 \%$ patients receiving semaglutide and $8.9 \%$ patients receiving placebo (HR: 0.74, 95\% Cl: 0.58-0.95; $\mathrm{p}<0.001$ for non-inferiority and $\mathrm{p}=0.02$ for superiority). Rates of $\mathrm{Ml}$ were non-significantly lower (HR: 0.74, 95\% Cl: 0.51-1.08), and rates of stroke were significantly lower (HR: 0.61, 95\% Cl: 0.38-0.99) with semaglutide.
In the EXSCEL trial, with exenatide, 14,752 patients with T2D with and without pre-existing CV disease were randomized to once-weekly $2 \mathrm{mg}$ extended-release exenatide or placebo. ${ }^{84}$ The primary outcome was a composite of $\mathrm{CV}$ death, MI or stroke. After a median follow-up of 3.2 years, the primary outcome occurred in $11.4 \%$ patients receiving exenatide and $12.2 \%$ receiving placebo (HR: $0.91,95 \% \mathrm{Cl}$ : $0.83-1.00$; non-inferiority $\mathrm{p}<0.001$; superiority $\mathrm{p}=0.06$ ). The rates for the individual CV outcomes and hospitalization for HF did not differ between groups. All-cause mortality was significantly lower with exenatide (HR: $0.86,95 \% \mathrm{Cl}$ : 0.77-0.97).

In the HARMONY OUTCOMES trial, with albiglutide, 9,463 patients with T2D and CV disease were randomized to weekly albiglutide (30-50 mg) or placebo. ${ }^{38}$ The primary outcome was a composite of CV death, MI or stroke. After a median follow-up of 1.6 years, the primary outcome occurred in $7 \%$ patients receiving albiglutide and $9 \%$ patients receiving placebo (HR: $0.78,95 \% \mathrm{Cl}$ : 0.68-0.90). The trial showed the non-inferiority $(p<0.001)$ and superiority $(p<0.0006)$ of albiglutide to placebo. Use of albiglutide was associated with a lower rate of $\mathrm{MI}$ (HR: $0.75,95 \% \mathrm{Cl}$ : 0.61-0.90) but not of stroke, CV death or all-cause mortality.

Finally, the REWIND trial, with dulaglutide, evaluated major CV outcomes with weekly dulaglutide in 9,901 patients with T2D, 69\% of whom did not have prior CV disease. ${ }^{41}$ The study had a median follow-up of more than 5 years, which is longer than other GLP-1 receptor agonist trials. Dulaglutide significantly reduced the composite endpoint of CV death, non-fatal MI or nonfatal stroke compared with placebo (HR: 0.88, 95\% Cl: 0.79-0.99; $\mathrm{p}=0.026$ for superiority). There was no reduction in CV death (dulaglutide vs. placebo: $6.4 \%$ vs. $7.0 \%$, $\mathrm{p}=0.21$ ) and non-fatal $\mathrm{MI}$ (dulaglutide vs. placebo: $4.1 \%$ vs. $4.3 \%, p=0.65$ ), while there was a significant reduction in non-fatal stroke (dulaglutide vs. placebo: $2.7 \%$ vs. $3.5 \%$, $\mathrm{p}=0.017$ ). Furthermore, dulaglutide did not reduce the hospitalization for HF compared to placebo ( $4.3 \%$ vs. $4.6 \%, p=0.46)$.

\section{SGLT-2i}

Many hypotheses have been suggested in order to explain the beneficial effect of SGLT-2i on CV disease and mortality, especially HF (Table 2). ${ }^{85-88}$ It is known that SGLT-2i reduce the levels of uric acid and, therefore, their uricosuric action has been proposed for their cardioprotective action. However, a recent trials showed that lowering uric acid with febuxostat might increase mortality rates. ${ }^{89}$ Furthermore, due to their diuretic action, SGLT-2i cause a small but significant reduction of blood pressure (35/1-3 mmHg). ${ }^{90}$ In the EMPA-REG OUTCOME mean blood 
pressure decreased from $135.3 / 76.6 \mathrm{mmHg}$ at baseline to $131.3 / 75.1 \mathrm{mmHg}$ at end of the study, while in CANVAS and DECLARE-TIMI 58 studies, mean blood pressure decreased from $136.4 / 77.6$ to $132.5 / 76.2$ and from $135.1 / 77.6$ to $132.3 / 75.8 \mathrm{mmHg}$, respectively. ${ }^{91,92}$ It must be mentioned that in the above trials the reduction of blood pressure was not associated with reduction of stroke and $\mathrm{MI} .{ }^{92} \mathrm{~A}$ recent study, in 42 healthy subjects randomized to dapagliflozin or bumetanide, showed that osmotic diuresis with dapagliflozin produces a 2 -fold greater reduction in interstitial compared with blood volume, while the relevant reduction with bumetanide was 0.8 -fold..$^{93}$ The authors suggest that the CV benefit of the SGLT- $2 \mathrm{i}$ is partly explained by their diuretic action. SGLT-2i decrease the fluid in the interstitial space and not the whole-intravascular volume, as result of not arterial underfilling. Finally, SGLT-2i therapy is accompanied by calorie loss due to osmotic diuresis, reducing the whole fat mass. ${ }^{94}$

The SGLT-2 inhibition in pancreatic alpha-cells induce glucagon secretion, affecting hepatic ketogenesis and circulating ketone levels. Increased circulating ketone levels are thought to be an efficient source of adenosine triphospate (ATP) for the heart. The heart is the organ with the highest energy expenditure and $70 \%$ originates from fatty acid oxidation. When heart's oxidize ketone bodies are used as energy source at the expense of fatty acid and glucose oxidation, which are less energetically efficient, less ATP synthesis per molecule of oxygen is needed. Against this hypothesis, it has been argued that the mechanisms of ketone accumulation have not been completely clarified and that in heart failure, the myocardium is already switched to ketone bodies use. ${ }^{94-98}$ In addition, SGLT-2i have direct action on cardiomyocytes: they inhibit the sodium-hydrogen exchanger-1, lower cytosolic $\mathrm{Na}$ and shift intracellular calcium from the cytosol to the mitochondria. ${ }^{92,99-101}$

The EMPAREG OUTCOME trial, with empagliflozin, randomized 7,028 patients with established CV disease to placebo, empagliflozin $10 \mathrm{mg}$ or empagliflozin $25 \mathrm{mg}$ for 3.1 years. The primary endpoint was the 3-point MACE including CV mortality, non-fatal MI and non-fatal stroke. ${ }^{8}$ Patients randomized to empagliflozin group showed a significant reduction in the primary endpoint (HR: 0.86, 95\% Cl: 0.74-0.99; $\mathrm{p}=0.04$ for superiority; absolute risk reduction $1.6 \%)$. This was driven predominantly by a substantial reduction in CV death (HR: 0.62, 95\% Cl: 0.49-0.77), whereas $\mathrm{Ml}$ and stroke were not significantly different. In addition, patients treated with empagliflozin had a $35 \%$ reduction in hospitalization for HF compared with placebo (HR: $0.65,95 \% \mathrm{Cl}: 0.50-0.85)$ and $32 \%$ risk reduction in all-cause mortality (HR: $0.68,95 \% \mathrm{Cl}$ : 0.57-0.82).
No difference was observed in the rate of fatal/non-fatal stroke (HR: 1.18, 95\% Cl: 0.89-1.56). The participants that have self-reported history of coronary artery bypass surgery treated with empagliflozin had reductions in CV events and all-cause mortality, HF hospitalization and in the worsening of nephropathy ${ }^{102}$, while there were no differences regarding the above outcomes between the two sexes. ${ }^{103}$ In another analysis of EMPAREG OUTCOME trial, including patients with CKD at baseline [eGFR $<60$ $\mathrm{mL} / \mathrm{min} / 1.73 \mathrm{~m}^{2}$ and/or UACR $>300 \mathrm{mg} / \mathrm{g}$ ], empagliflozin reduced CV death by $29 \%$ (HR: $0.71,95 \% \mathrm{Cl}: 0.52-0.98)$, all-cause mortality by $24 \%$ (HR: $0.76,95 \% \mathrm{Cl}: 0.59-0.99)$, hospitalization for HF by $39 \%$ (HR: $0.61,95 \% \mathrm{Cl}: 0.42-0.87$ ) and all-cause hospitalization by $19 \%$ (HR: $0.81,95 \% \mathrm{Cl}$ : $0.72-0.92$ ) compared to placebo. ${ }^{104}$

In the CANVAS Programme, CANVAS and CANVAS-renal (CANVAS-R) studies, 10,142 participants with T2D and high CV risk were followed for a mean of 188.2 weeks. ${ }^{9}$ The primary outcome in both trials was a composite of CV death, non-fatal MI or non-fatal stroke. Canagliflozin was associated with a significant reduction in the risk of MACE (HR: 0.86, 95\% Cl: 0.75-0.97, p =0.02 for superiority), hospitalization for HF (HR: $0.67,95 \% \mathrm{Cl}: 0.52-0.87)$ and not statistically significant, reduction in all-cause mortality (HR $0.87,95 \% \mathrm{Cl} 0.74-1.01)$. The risk of stroke was not different between groups (HR: 0.87, 95\% Cl: 0.67-1.09). Another analysis of CANVAS trial in 4 subgroups (eGFR $<45,45$ to $<60,60$ to $<90$ and $>90 \mathrm{~mL} / \mathrm{min} / 1.73 \mathrm{~m}^{2}$ ) showed that the reduction in the primary outcome for the overall trial population was similar among the 4 subgroups and for patients with and without CKD ( $p$ for heterogeneity $=0.33$ and 0.08 , respectively).9 Finally, another analysis of CANVAS trial confirmed the observed benefit in the reduction of the risk of hospitalization for HF, in patients having history of HF at baseline. ${ }^{105}$

In the DECLARE TIMI-58 trial, with dapagliflozin, whereas participated mainly patients in primary prevention, 17,160 patients with T2D were followed over a period of 4.2 years. ${ }^{10}$ Participants either had established CV disease or were at risk for CV disease. The primary safety outcome was a composite of CV death, MI or ischaemic stroke. The primary efficacy outcomes were MACE and a composite of CV death or hospitalization for HF. In the primary safety analysis, dapagliflozin met the pre-specified non-inferiority criterion (upper boundary of the $95 \% \mathrm{Cl}<1.3, \mathrm{p}<0.001$ ). In the efficacy analyses, dapagliflozin was not superior to placebo in reducing the rate of MACE (8.8 versus $9.4 \%$,respectively, HR: $0.93,95 \% \mathrm{Cl} 0.84-1.03, \mathrm{p}=0.17$ ), but showed lower rate of CV death or hospitalization for HF (4.9\% versus 5.8\%, HR: 0.83, 95\% Cl: 0.73-0.95). Dapagliflozin decreased the risk of hospitalization for HF (HR: 0.73, 95\% 
Cl: 0.61-0.88), while CV death events were similar in the 2 groups (HR 0.98, 95\% Cl 0.82-1.17). Furthermore, dapagliflozin was not associated with a significant reduction in MI (HR: 0.89, 95\% Cl: 0.77-1.01), ischemic stroke (HR: 1.01, 95\% Cl: 0.84-1.21) and all-cause mortality (HR: 0.98, 95\% Cl: 0.82-1.17).

Recently the results of DAPA-HF trial were published showing a positive effect of dapagliflozin in patients with $\mathrm{HF}$ and reduced ejection fraction. ${ }^{106}$ In the DAPA-HF trial 4,744 patients (with and without diabetes) with New York Heart Association class II, III, or IV HF and an ejection fraction of $40 \%$ or less assigned randomly to receive either dapagliflozin (at a dose of $10 \mathrm{mg}$ once daily) or placebo, in addition to recommended therapy. The primary outcome was a composite of worsening HF (hospitalization or an urgent visit resulting in intravenous therapy for HF) or CV death. The participants were followed over 18.2 months. Dapagliflozin reduced significantly the primary outcome compared to placebo ( $16.3 \%$ vs $21.2 \%$, HR: $0.74 ; 95 \% \mathrm{Cl}$ : $0.65-0.85, \mathrm{p}<0.001)$, the first worsening HF event $(10 \%$ vs $13.7 \%$, HR: $0.70 ; 95 \% \mathrm{Cl}: 0.59-0.83), \mathrm{CV}$ death $(9.6 \%$ vs 11.5\%, HR: $0.70 ; 95 \% \mathrm{Cl}: 0.59-0.83)$, and all-cause mortality (11.6\% vs 13.\%, HR: 0.83; 95\% Cl: 0.71 - 0.97). These findings were similar between participants with and no history of diabetes. The frequency of adverse events related to volume depletion, renal dysfunction, and hypoglycemia did not differ between treatment groups. Thus, dapagliflozin demonstrated the beneficial action in patients with HF with reduced ejection fraction regardless of the presence of diabetes.

\section{CONCLUSION}

It is well established that in order to slow the progression of CKD and to prevent Cv, a multifactorial approach of patients with T2D, including glycaemic control, blood pressure, lipid profile and lifestyle interventions, is needed..$^{10,107}$ According to recent guidelines of the American Diabetes Association ${ }^{108}$ metformin remains the first choice of antidiabetic therapy in combination with lifestyle modification (including weight management and physical activity). If a second antidiabetic agent is needed for glycaemic control, then the presence of established atherosclerotic cardiovascular disease (ASCVD) is mandatory for the next step in antidiabetic therapy. If there is established ASCVD or indicators of high-risk ASCVD risk (age $\geq 55$ years with coronary or carotid or lower extremity artery stenosis $>50 \%$, left ventricular hypertrophy), GLP-1 receptor agonists with proven CV benefit (liraglutide, semaglutide, dulaglutide) are preferred. Alternatively, SGLT-2i with proven CV benefit (empagliflozin, canagliflozin, dapagliflozin) are preferred if eGFR is adequate. If HF (with reduced ejection fraction, particularly with left ventricular ejection fraction <45\%) or CKD predominates (defined as the presence of eGFR $30-60 \mathrm{ml} / \mathrm{min} / 1.73 \mathrm{~m}^{2}$ or UACR $>30 \mathrm{mg} / \mathrm{g}$, particularly $>300$ $\mathrm{mg} / \mathrm{g}$ ), the use of SGLT- $2 \mathrm{i}$ with evidence of reducing $\mathrm{HF}$ or/and CKD progression are preferred if eGFR adequate. If eGFR is not adequate, then GLP-1 receptor agonists with proven CV benefit are preferred. Consequently, the proven cardioprotective and renoprotective action of SGLT-2i and GLP-1 receptor agonists dictates the use of these in the management of T2D in general practice.

\section{ПЕРІАНЧН}

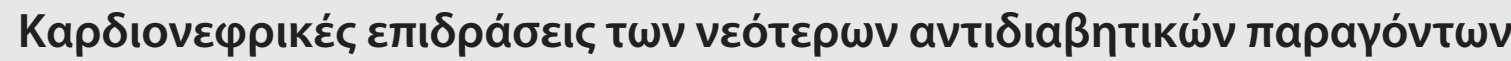

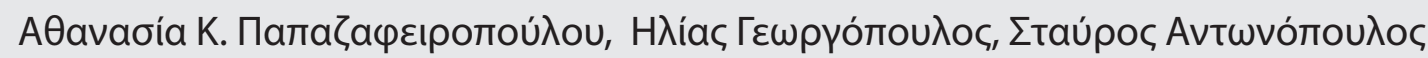

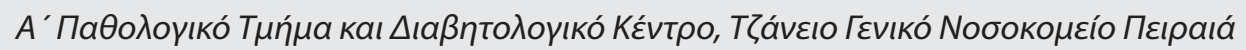

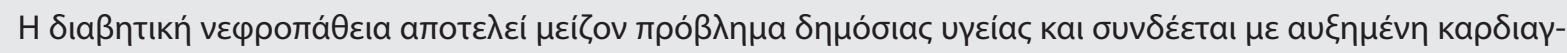

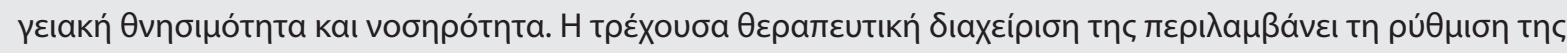

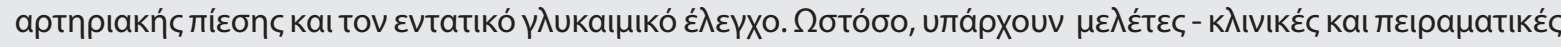

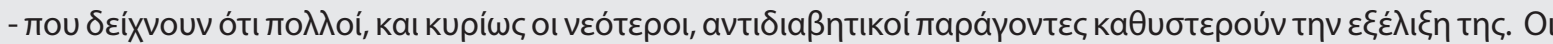

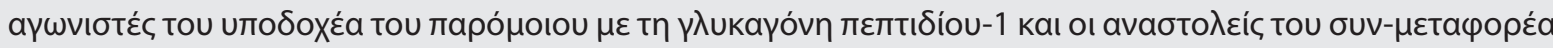

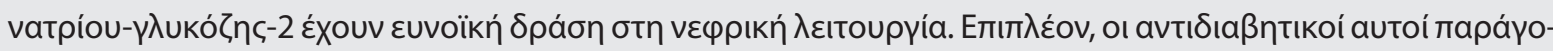

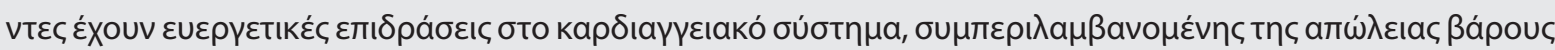

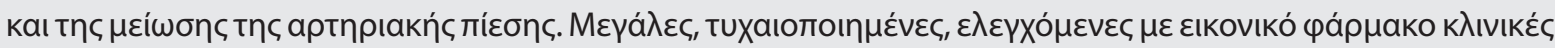

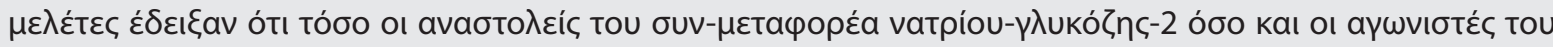

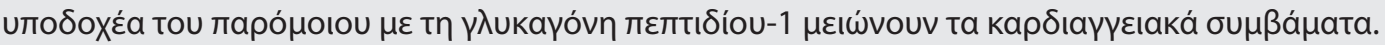




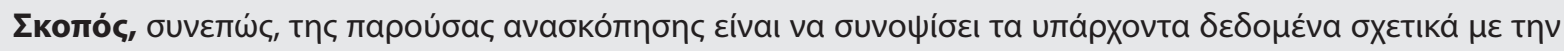

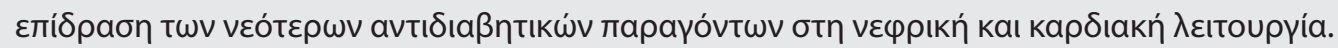

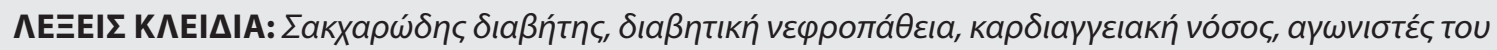

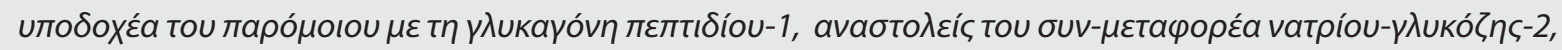

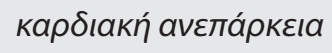

\section{REFERENCES}

1. World Health Organization WHO. [Internet]. Global report on Diabetes. 2016 [cited 2020 Feb 27]. Available from: https://www.who.int/diabetes/global-report/en/

2. Group IDFDA. Update of mortality attributable to diabetes for the IDF Diabetes Atlas: Estimates for the year 2013. Diabetes Res Clin Pract. 2015 Sep;109(3):461-5.

3. Sarwar N, Gao P, Seshasai SR. Diabetes mellitus, fasting blood glucose concentration, and risk of vascular disease: a collaborative meta-analysis of 102 prospective studies. Lancet. 2010; 375: 2215-22. Lancet. 2010 Jun;375(9733):2215-22.

4. Reutens AT, Atkins RC. Epidemiology of diabetic nephropathy. Contrib Nephrol. 2011 Jun;170:1-7.

5. Go AS, Chertow GM, Fan D, McCulloch CE, Hsu CY. Chronic kidney disease and the risks of death, cardiovascular events, and hospitalization. N Engl J Med. 2004 Sep;351(13):1296-305.

6. Adler Al, Stevens RJ, Manley SE. Development and progression of nephropathy in type 2 diabetes: The United Kingdom Prospective Diabetes Study (UKPDS 64). Kidney Int. 2003 Jan;63(1):225-32.

7. Schernthaner G, Schernthane-Reiter MH, Schernthaner GH. EMPAREG and other cardiovascular outcome trials of glucose-lowering agents: implications for future treatment strategies in type 2 diabetes mellitus. Clin Ther. 2016 Jun;38(6):1288-1298.

8. Zinman B, Wanner C, Lachin JM, Fitchett D, Bluhmki E, Hantel S, et al. EMPA-REG OUTCOME Investigators. Empagliflozin, cardiovascular outcomes, and mortality in type 2 diabetes. N Engl J Med. 2015 Nov;373(22):2117-28.

9. Neal B, Perkovic V, Mahaffey KW, de Zeeuw D, Fulcher G, Erondu N, et al. CANVAS Program Collaborative Group. Canagliflozin and Cardiovascular and Renal Events in Type 2 Diabetes. N Engl J Med. 2017 Aug;377(7):644-657.

10. Wiviott SD, Raz I, Bonaca MP, Mosenzon O, Kato ET, Cahn A, et al. DECLARE-TIMI 58 Investigators. Dapagliflozin and cardiovascular outcomes in type 2 diabetes. $\mathrm{N}$ Engl J Med. 2019 Jan;380(4):347-57.

11. Marso SP, Daniels GH, Brown-Frandsen K, Kristensen P, Mann JF, Nauck MA, et al. LEADER Steering Committee; LEADER Trial Investigators. Liraglutide and cardiovascular outcomes in type 2 diabetes. N Engl J Med. 2016 Jul;375(4):311-22.

12. Marso SP, Bain SC, Consoli A, Eliaschewitz FG, Jódar E, Leiter LA, et al. SUSTAIN-6 Investigators. Semaglutide and cardiovascular outcomes in patients with type 2 diabetes. N Engl J Med. 2016 Nov;375(19):1834-44.

13. Lim AKH. Diabetic nephropathy-complications and treat- ment. Int J Nephrol Renovasc Dis. 2014 Oct;7:361-81.

14. Diabetes Control and Complications Trial Research Group, Nathan DM, Genuth S, Lachin J, Cleary P, Crofford O, Davis $M$, et al. The effect of intensive treatment of diabetes on the development and progression of long-term complications in insulin-dependent diabetes mellitus. N Engl J Med. 1993 Sep;329(14):977-86.

15. UK Prospective Diabetes Study (UKPDS) Group Intensive blood-glucose control with sulphonylureas or insulin compared with conventional treatment and risk of complications in patients with type 2 diabetes (UKPDS 33). Lancet. 1998 Sep;352(9131):837-53.

16. Brenner BM, Cooper ME, de Zeeuw D, Keane WF, Mitch WE, Parving $\mathrm{HH}$, et al. RENAAL Study Investigators. Effects of losartan on renal and cardiovascular outcomes in patients with type 2 diabetes and nephropathy. $\mathrm{N}$ Engl J Med. 2001 Sep;345(12):861-9.

17. Lewis EJ, Hunsicker LG, Clarke WR, BerlT, PohI MA, Lewis JB, et al. Collaborative Study Group. Renoprotective effect of the angiotensin-receptor antagonist irbesartan in patients with nephropathy due to type 2 diabetes. $\mathrm{N}$ Engl J Med. 2001 Sep;345(12):851-60.

18. Gaede $\mathrm{P}$, Lund-Andersen $\mathrm{H}$, Parving HH, Pedersen O. Effect of a multifactorial intervention on mortality in type 2 diabetes. N Engl J Med. 2008 Feb;358(6):580-91.

19. DCCT/EDIC Research Group. Effect of intensive diabetes treatment on albuminuria in type 1 diabetes: long-term follow-up of the Diabetes Control and Complications Trial and Epidemiology of Diabetes Interventions and Complications study. Lancet Diabetes Endocrinol. 2014 Oct;2(10):793-800.

20. DCCT/EDIC Research Group, de Boer IH, Sun W, Cleary PA, Lachin JM, Molitch ME, Steffes MW, et al. DCCT/EDIC Research Group. Intensive diabetes therapy and glomerular filtration rate in type 1 diabetes. $\mathrm{N}$ Engl $\mathrm{J}$ Med. 2011 Dec;365(25):2366-76.

21. Bilous R. Microvascular disease: what does the UKPDS tell us about diabetic nephropathy? Diabet Med. 2008 Aug;25(Suppl. 2):25-29.

22. ADVANCE Collaborative Group, Patel A, MacMahon $S$, Chalmers J, Neal B, Billot L, Woodward M, et al. Intensive blood glucose control and vascular outcomes in patients with type 2 diabetes. N Engl J Med. 2008 Jun;358(24): 2560-72.

23. Ismail-Beigi F, Craven T, Banerji MA, Basile J, Calles J, Cohen $\mathrm{RM}$, et al. ACCORD trial group. Effect of intensive treatment of hyperglycaemia on microvascular outcomes in type 2 diabetes: An analysis of the ACCORD randomised trial. Lancet. 2010 Aug;376(9739):419-30.

24. Duckworth W, Abraira C, Moritz T, Reda D, Emanuele N, 
Reaven PD, et al. VADT Investigators. Glucose control and vascular complications in veterans with type 2 diabetes. N Engl J Med. 2009 Jan;360(2):129-39.

25. Tonneijck L, Muskiet MH, Smits MM, van Bommel EJ, Heerspink HJ, van Raalte DH, et al. Glomerular Hyperfiltration in Diabetes: Mechanisms, Clinical Significance, and Treatment. J Am Soc Nephrol. 2017 Apr;28(4):1023-39.

26. Tonneijck L, Smits MM, Muskiet MH, Hoekstra T, Kramer $\mathrm{MH}$, Danser AH, et al. Renal Effects of DPP-4 Inhibitor Sitagliptin or GLP-1 Receptor Agonist Liraglutide in Overweight Patients With Type 2 Diabetes: A 12-Week, Randomized, Double-Blind, Placebo-Controlled Trial. Diabetes Care. 2016 Nov;39(11):2042-50.

27. Tang-Christensen M, Larsen PJ, Göke R, Fink-Jensen A, Jessop DS, Møller M, et al. Central administration of GLP1-(7-36) amide inhibits food and water intake in rats. Am J Physiol. 1996 Oct;271 (4 Pt 2):R848-56.

28. Crajoinas RO, Oricchio FT, Pessoa TD, Pacheco BP, Lessa LM, Malnic G, et al. Mechanisms mediating the diuretic and natriuretic actions of the incretin hormone glucagon-like pep-tide-1. Am J Physiol Renal Physiol. 2011 Aug;301(2):F355-63.

29. Lytvyn Y, Bjornstad P, van Raalte DH, Heerspink HL, Cherney DZI. The New Biology of Diabetic Kidney DiseaseMechanisms and Therapeutic Implications. Endocr Rev. 2020 Apr;41(2). pii: bnz010.

30. Pfeffer MA, Claggett B, Diaz R, Dickstein K, Gerstein HC, Køber LV, et al. Lixisenatide in patients with type 2 diabetes and acute coronary syndrome. N Engl J Med. 2015 Dec;373(23):2247-57.

31. Von Scholten BJ, Lajer M, Goetze JP, Persson F, Rossing P. Time course and mechanisms of the antihypertensive and renal effects of liraglutide treatment. Diabet Med. 2015 Mar;32(3):343-52

32. Tonneijck L, Smits MM, van Raalte DH Muskiet MH. Incretin-based drugs and renoprotection is hyperfiltration key? Kidney Int. 2015 Mar;87(3):660-1.

33. Mann JFE, Ørsted DD, Brown-Frandsen K, Marso SP, Poulter NR, Rasmussen S, et al. LEADER Steering Committee and Investigators. Liraglutide and renal outcomes in type 2 diabetes. N Engl J Med. 2017 Aug;377(9):839-48.

34. Von Scholten BJ, Hansen TW, Goetze JP, Persson F, Rossing P. Glucagon-like peptide 1 receptor agonist (GLP-1 RA): long-term effect on kidney function in patients with type 2 diabetes. J Diabetes Complications. 2015 Jul;29(5):670-4.

35. Von Scholten BJ, Persson F, Rosenlund S, Hovind P, Faber J, Hansen TW, et al. The effect of liraglutide on renal function: A randomized clinical trial. Diabetes Obes Metab. 2017 Feb;19(2):239-47.

36. Davies MJ, Bergenstal R, Bode B, Kushner RF, Lewin A, Skjøth TV, et al. NN8022-1922 Study Group. Efficacy of liraglutide for weight loss among patients with type 2 diabetes: The SCALE Diabetes Randomized Clinical Trial. JAMA. 2015 Aug;314(7):687-99.

37. Bethel MA, Mentz RJ, Merrill P, Lokhnygina Y, Buse JB, Chan JC, et al. Renal outcomes in the EXenatide Study of Cardiovascular Event Lowering (EXSCEL). Diabetes. 2018 Jul;67:522-P.

38. Hernandez AF, Green JB, Janmohamed S, D'Agostino RB Sr, Granger CB, Jones NP, et al. Harmony Outcomes committees and investigators. Albiglutide and cardio- vascular outcomes in patients with type 2 diabetes and cardiovascular disease (Harmony Outcomes): a doubleblind, randomized placebo-controlled trial. Lancet. 2018 Oct;392(10157):1519-29.

39. Tuttle KR, Lakshmanan MC, Rayner B, Busch RS, Zimmermann AG, Woodward DB, et al. Dulaglutide versus insulin glargine in patients with type 2 diabetes and moderate-to-severe chronic kidney disease (AWARD-7): a multicentre, open-label, randomised trial. Lancet Diabetes Endocrinol. 2018 Aug;6(8):605-17.

40. Muskiet MHA, Tonneijck L, Huang Y, Liu M, Saremi A, Heerspink HJL, et al. Lixisenatide and renal outcomes in patients with type 2 diabetes and acute coronary syndrome: an exploratory analysis of the ELIXA randomised, placebo-controlled trial. Lancet Diabetes Endocrinol. 2018 Nov;6:859-69.

41. Gerstein HC, Colhoun HM, Dagenais GR, Diaz R, Lakshmanan M, Pais P, et al. REWIND Trial Investigators. Dulaglutide and renal outcomes in type 2 diabetes: an exploratory analysis of the REWIND randomised, placebo-controlled trial. Lancet. 2019 Jul;394(10193):131-8.

42. Vlotides G, Mertens PR. Sodium-glucose cotransporter-2 inhibitors: mechanisms, metabolic effects and implications for the treatment of diabetic patients with chronic kidney disease. Nephrol Dial Transplant. 2015 Aug;30(8):1272-6.

43. Gilbert RE. Sodium-glucose linked transporter-2 inhibitors: potential for renoprotection beyond blood glucose lowering. Kidney Int. 2014 Oct;86(4):693-700.

44. Hostetter TH, Rennke HG, Brenner BM. The case for intrarenal hypertension in the initiation and progression of diabetic and other glomerulopathies. Am J Med. 1982 Mar;72(3):375-80.

45. Jerums G, Premaratne E, Panagiotopoulos S, Maclsaac RJ. The clinical significance of hyperfiltration in diabetes. Diabetologia. 2010 Oct;53(10):2093-104.

46. Herney DZ, Perkins BA, Soleymanlou N, Maione M, Lai $V$, Lee $A$, et al. Renal hemodynamic effect of sodiumglucose cotransporter 2 inhibition in patients with type 1 diabetes mellitus. Circulation. 2014 Feb;129(5):587-97.

47. Vallon V, Muhlbauer B, Osswald H. Adenosine and kidney function. Physiol Rev. 2006 Jul;86(3):901-40.

48. O'Neill J, Fasching A, Pihl L, Patinha D, Franzén S, Palm F. Acute SGLT inhibition normalizes $\mathrm{O} 2$ tension in the renal cortex but causes hypoxia in the renal medulla in anaesthetized control and diabetic rats. Am J Physiol Renal Physiol. 2015 Aug;309(3):F227-34.

49. Ojima A, Matsui T, Nishino Y, Nakamura N, Yamagishi S. Empagliflozin, an inhibitor of sodium-glucose cotransporter 2 exerts anti-inflammatory and anti-fibrotic effects on experimental diabetic nephropathy partly by suppressing AGEs-receptor axis. Horm Metab Res. 2015 Aug;47(9):686-92.

50. Panchapakesan U, Pegg K, Gross S, Komala MG, Mudaliar $\mathrm{H}$, Forbes J, et al. Effects of SGLT2 inhibition in human kidney proximal tubular cells renoprotection in diabetic nephropathy. PLoS One. 2013 Feb;8(2):e54442.

51. Salim HM, Fukuda D, Yagi S, Soeki T, Shimabukuro M, Sata M. Glycemic control with ipragliflozin, a novel selective SGLT2 inhibitor, ameliorated endothelial dysfunction in streptozotocin-induced diabetic mouse. Front Cardiovasc 
Med. 2016 Oct;3:43.

52. Terami N, Ogawa D, Tachibana H, Hatanaka T, Wada J, Nakatsuka A, et al. Long-term treatment with the sodium glucose co-transporter-2 inhibitor, dapagliflozin, ameliorates glucose homeostasis and diabetic nephropathy in db/db mice. PLoS One. 2014 Jun 24;9(6):e100777.

53. Cherney DZ, Perkins BA, Soleymanlou N, Maione M, Lai $V$, Lee $A$, et al. Renal hemodynamic effect of sodiumglucose cotransporter 2 inhibition in patients with type 1 diabetes mellitus. Circulation. 2014 Feb;129(5):587-97.

54. Neuen BL, Ohkuma T, Neal B, Matthews DR, de Zeeuw D, Mahaffey KW, et al. Cardiovascular and renal outcomes with canagliflozin according to baseline kidney function. Circulation. 2018 Oct;138(15):1537-50.

55. Perkovic V, de Zeeuw D, Mahaffey KW, Fulcher G, Erondu $\mathrm{N}$, Shaw W, et al. Canagliflozin and renal outcomes in type 2 diabetes: results from the CANVAS Program randomised clinical trials. Lancet Diabetes Endocrinol. 2018 Sep;6(9):691-704

56. Zelniker TA, Wiviott SD, Raz I, Im K, Goodrich EL, Bonaca MP, et al. SGLT2 inhibitors for primary and secondary prevention of cardiovascular and renal outcomes in type 2 diabetes: a systematic review and meta-analysis of cardiovascular outcome trials. Lancet. 2019 Jan;393(10166):319.

57. De Zeeuw D, Remuzzi G, Parving H, Keane WF, Zhang Z, Shahinfar S, et al. Proteinuria, a target for renoprotection in patients with type 2 diabetic nephropathy: lessons from RENAAL. Kidney Int. 2004 Jun;65(6):2309-20.

58. Atkins RC, Briganti EM, Lewis JB, Hunsicker LG, Braden G, Champion de Crespigny PJ, et al. Proteinuria reduction and progression to renal failure in patients with type 2 diabetes mellitus and overt nephropathy. Am J Kidney Dis. 2005 Feb;45(2):281-7.

59. Perkovic V, Jardine MJ, Neal B, Bompoint S, Heerspink $\mathrm{HJL}$, Charytan DM, et al. CREDENCE study investigators. Canagliflozin and Renal Outcomes in Type 2 Diabetes and Nephropathy. N Engl J Med. 2019 Jun;380(24):2295-306.

60. Heerspink HJL, Stefansson BV, Chertow GM, Correa-Rotter R, Greene T, Hou FF, et al. DAPA-CKD Investigators. Rationale and protocol of the Dapagliflozin And Prevention of Adverse outcomes in Chronic Kidney Disease (DAPA-CKD) randomized controlled trial. Nephrol Dial Transplant. 2020 Feb;35(2):274-82.

61. Newman JD, Vani AK, Aleman JO, Weintraub HS, Berger JS, Schwartzbard AZ. The changing landscape of diabetes therapy for cardiovascular risk reduction: JACC state-ofthe-art review. J Am Coll Cardiol. 2018 Oct;72(15):1856-69.

62. McHugh KR, DeVore AD, Mentz RJ, Edmonston D, Green $J B$, Hernandez AF. The emerging role of novel antihyperglycemic agents in the treatment of heart failure and diabetes: A focus on cardiorenal outcomes. Clin Cardiol. 2018 Sep;41(9):1259-67.

63. Bunck MC, Diamant $M$, Eliasson $B$, Cornér $A$, Shaginian RM, Heine RJ, et al. Exenatide affects circulating cardiovascular risk biomarkers independently of changes in body composition. Diabetes Care. 2010 Aug;33(8):1734-7.

64. Jendle J, Nauck MA, Matthews DR, Frid A, Hermansen K, Düring $M$, et al. LEAD-2 and LEAD-3 Study Groups. Weight loss with liraglutide, a once-daily human glucagon-like peptide- 1 analogue for type 2 diabetes treatment as monotherapy or added to metformin, is primarily as a result of a reduction in fat tissue. Diabetes Obes Metab. 2009 Dec;11(12):1163-72.

65. van Can J, Sloth B, Jensen CB, Flint A, Blaak EE, Saris WH. Effects of the once-daily GLP-1 analog liraglutide on gastric emptying, glycemic parameters, appetite and energy metabolism in obese, non-diabetic adults. Int J Obes (Lond). 2014 Jun;38(6):784-93.

66. Pi-Sunyer X, Astrup A, Fujioka K, Greenway F, Halpern A, Krempf M, et al. SCALE Obesity and Prediabetes NN80221839 Study Group. A randomized, controlled trial of 3.0 mg of liraglutide in weight management. N Engl J Med. 2015 Jul;373(1):11-22.

67. Mehta A, Marso SP, Neeland IJ. Liraglutide for weight management: a critical review of the evidence. Obes Sci Pract. 2017 Mar;3(1):3-14.

68. Sun F, Wu S, Guo S, Yu K, Yang Z, Li L, et al. Impact of GLP-1 receptor agonists on blood pressure, heart rate and hypertension among patients with type 2 diabetes: a systematic review and network meta-analysis. Diabetes Res Clin Pract. 2015 Oct;110(1):26-37.

69. Nauck MA, Meier JJ, Cavender MA, Abd El Aziz M, Drucker DJ. Cardiovascular actions and clinical outcomes with glucagon-like peptide-1 receptor agonists and dipeptidyl peptidase-4 inhibitors. Circulation. 2017 Aug;136(9):84970.

70. Drucker DJ. The biology of incretin hormones. Cell Metab. 2006 Mar;3(3):153-65.

71. Drucker DJ. The cardiovascular biology of glucagon-like peptide-1. Cell Metab. 2016 Jul;24(1):15-30.

72. Gutzwiller JP, Tschopp S, Bock A, Zehnder CE, Huber AR, Kreyenbuehl $M$, et al. Glucagon-like peptide 1 induces natriuresis in healthy subjects and in insulin-resistant obese men. J Clin Endocrinol Metab. 2004 Jun;89(6):305561.

73. Muskiet MH, Smits MM, Morsink LM, Diamant M. The gutrenal axis: do incretin-based agents confer renoprotection in diabetes? Nat Rev Nephrol. 2014 Feb;10(2):88-103.

74. Skov J, Dejgaard A, Frøkiær J, Holst JJ, Jonassen T, Rittig $\mathrm{S}$, et al. Glucagon-like peptide-1 (GLP-1): effect on kidney hemodynamics and renin-angiotensin-aldosterone system in healthy men. J Clin Endocrinol Metab. 2013 Apr;98(4):E664-71.

75. Hsieh J, Longuet C, Baker CL, Qin B, Federico LM, Drucker $D J$, et al. The glucagon-like peptide 1 receptor is essential for postprandial lipoprotein synthesis and secretion in hamster sand mice. Diabetologia. 2010 Mar;53(3):552-61.

76. Xiao C, Bandsma RH, Dash S, Szeto L, Lewis GF. Exenatide, a glucagon-like peptide-1 receptor agonist, acutely inhibits intestinal lipoprotein production in healthy humans. Arterioscler Thromb Vasc Biol. 2012 Jun;32(6):1513-9.

77. Sancho V, Trigo MV, Martin-Duce A, Gonz Lez N, Acitores A, Arnés L, et al. Effect of GLP-1 on D-glucose transport, lipolysis and lipogenesis in adipocytes of obese subjects. Int J Mol Med. 2006 Jun;17(6):1133-7.

78. El Bekay R, Coin-Araguez L, Fernandez-Garcia D, OlivaOlivera W, Bernal-López R, Clemente-Postigo M, et al. Effects of glucagon-like peptide-1 on the differentiation and metabolism of human adipocytes. Br J Pharmacol. 2016 Jun;173(11):1820-34.

79. Margulies KB, Hernandez AF, Redfield MM, Givertz MM, 
Oliveira GH, Cole R, et al. NHLBI Heart Failure Clinical Research Network. Effects of liraglutide on clinical stability among patients with advanced heart failure and reduced ejection fraction: a randomized clinical trial. JAMA. 2016 Aug;316(5):500-8.

80. Sokos GG, Nikolaidis LA, Mankad S, Elahi D, Shannon RP. Glucagon-like peptide-1 infusion improves left ventricular ejection fraction and functional status in patients with chronic heart failure. J Card Fail. 2006 Dec;12(9):694-9.

81. Nikolaidis LA, Mankad S, Sokos GG, Miske G, Shah A, Elahi $D$, et al. Effects of glucagon-like peptide-1 in patients with acute myocardial infarction and left ventricular dysfunction after successful reperfusion. Circulation. 2004 Mar;109(8):962-5.

82. Inoue T, Inoguchi T, Sonoda N, Hendarto H, Makimura $H$, Sasaki S, et al. GLP-1 analog liraglutide protects against cardiac steatosis, oxidative stress and apoptosis in streptozotocin-induced diabetic rats. Atherosclerosis. 2015 May;240(1):250-9.

83. Gaspari T, Brdar M, Lee HW, Spizzo I, Hu Y, Widdop RE, et al. Molecular and cellular mechanisms of glucagon-like peptide-1 receptor agonist-mediated attenuation of cardiac fibrosis. Diab Vasc Dis Res. 2016 Jan;13(1):56-68.

84. Holman RR, Bethel MA, Mentz RJ, Thompson VP, Lokhnygina Y, Buse JB, et al. EXSCEL Study Group. Effects of once-weekly exenatide on cardiovascular outcomes in type 2 diabetes. N Engl J Med. 2017 Sep;377(13):1228-39.

85. Lytvyn Y, Bjornstad P, Udell JA, Lovshin JA, Cherney DZI. Sodium glucose cotransporter-2 inhibition in heart failure: potential mechanisms, clinical applications, and summary of clinical trials. Circulation. 2017 Oct;136(17):1643-58.

86. Flores E, Santos-Gallego CG, Diaz-Mejía N, Badimon JJ. Do the SGLT-2 inhibitors offer more than hypoglycemic activity. Cardiovasc Drugs Ther. 2018 Apr;32(2):213-22.

87. Ferrannini E. Sodium-glucose co-transporters and their inhibition: clinical physiology. Cell Metab. 2017 Jul;26(1):27-38.

88. Scheen AJ. Cardiovascular effects of new oral glucoselowering agents: DPP-4 and SGLT-2 inhibitors. Circ Res. 2018 May;122(10):1439-59.

89. White WB, Saag KG, Becker MA, Borer JS, Gorelick PB, Whelton $A$, et al. CARES Investigators. Cardiovascular safety of febuxostat or allopurinol in patients with gout. N Engl J Med. 2018 Mar;378(13):1200-10.

90. Imprialos KP, Sarafidis PA, Karagiannis Al. Sodium-glucose cotransporter- 2 inhibitors and blood pressure decrease: a valuable effect of a novel antidiabetic class. J Hypertens. 2015 Nov;33(11):2185-97.

91. Papadopoulou E, Angeloudi E, Karras S, Sarafidis P. The optimal blood pressure target in diabetes mellitus: a quest coming to an end. J Hum Hypertens. 2018 Oct;32(10):64150.

92. Sarafidis PA, Lazaridis AA, Ruiz-Hurtado G, Ruilope LM. Blood pressure reduction in diabetes: lessons from ACCORD, SPRINT and EMPAREG OUTCOME. Nat Rev Endocrinol. 2017 Jun;13(6):365-74.

93. Hallow KM, Helmlinger G, Greasley PJ, McMurray JJV, Boulton DW. Why do SGLT2 inhibitors reduce heart failure hospitalization. A differential volume regulation hypothesis. Diabetes Obes Metab. 2018 Mar;20(3):479-87.
94. Bonner C, Kerr-Conte J, Gmyr V, Queniat G, Moerman E, Thévenet J, et al. Inhibition of the glucose transporter SGLT2 with dapagliflozin in pancreatic alpha cells triggers glucagon secretion. Nat Med. 2015 May;21 (5):512-7.

95. Burge MR, Hardy KJ, Schade DS. Short-term fasting is a mechanism for the development of euglycemic ketoacidosis during periods of insulin deficiency. J Clin Endocrinol Metab. 1993 May;76(5):1192-8.

96. Ferrannini E, Mark M, Mayoux E. CV protection in the EMPAREG OUTCOME Trial: a "thrifty substrate" hypothesis. Diabetes Care. 2016 Jul;39(7):1108-14.

97. Puchalska P, Crawford PA. Multidimensional roles of ketone bodies in fuel metabolism, signaling, and therapeutics. Cell Metab. 2017 Feb;25(2):262-84.

98. Lopaschuk GD, Verma S. Empagliflozin fuel hypothesis: not so soon. Cell Metab. 2016 Aug;24(2):200-2.

99. Baartscheer A, Schumacher CA, Wust RC, Fiolet JW, Stienen GJ, Coronel R, et al. Empagliflozin decreases myocardial cytoplasmic $\mathrm{Na}(\mathrm{p})$ through inhibition of the cardiac $\mathrm{Na} / \mathrm{H}$ exchanger in rats and rabbits. Diabetologia. 2017 Mar;60(3):568-73.

100. Uthman L, Baartscheer A, Bleijlevens B, Schumacher CA, Fiolet JWT, Koeman A, et al. Class effects of SGLT2 inhibitors in mouse cardiomyocytes and hearts: inhibition of $\mathrm{Na} / \mathrm{H}$ exchanger, lowering of cytosolic $\mathrm{Na}$ and vasodilation. Diabetologia. 2018 Mar;61(3):722-6.

101. Bertero E, Prates Roma L, Ameri P, Maack C. Cardiac effects of SGLT2 inhibitors: the sodium hypothesis. Cardiovasc Res. 2018 Jan; 114(1):12-8.

102. Verma $S$, Mazer CD, Fitchett $D$, et al. Empagliflozin reduces cardiovascular events, mortality and renal events in participants with type 2 diabetes after coronary artery bypass graft surgery: sub analysis of the EMPAREG OUTCOME (R) randomised trial. Diabetologia. 2018 Aug;61(8):1712-3.

103.Zinman B, Inzucchi SE, Wanner C, Hehnke U, George JT, Johansen OE, et al. EMPA-REG OUTCOME ${ }^{\circledR}$ investigators. Empagliflozin in women with type 2 diabetes and cardiovascular disease - an analysis of EMPAREG OUTCOME (R). Diabetologia. 2018 Jul;61(7):1522-7.

104. Wanner C, Lachin JM, Inzucchi SE, Fitchett D, Mattheus $M$, George J, et al. EMPA-REG OUTCOME Investigators. Empagliflozin and clinical outcomes in patients with type 2 diabetes mellitus, established cardiovascular disease, and chronic kidney disease. Circulation. 2018 Jan;137(2):119-29.

105. Radholm K, Figtree G, Perkovic V, Solomon SD, Mahaffey KW, de Zeeuw D, et al. Canagliflozin and heart failure in type 2 diabetes mellitus. Circulation. 2018 Jul;138(5):45868.

106. McMurray J, Solomon S, Inzucchi SE, Køber L, Kosiborod MN, Martinez FA, et al. DAPA-HF Trial Committees and Investigators. Dapagliflozin in Patients with Heart Failure and Reduced Ejection Fraction. N Engl J Med. 2019 Nov;381(21):1995-2008.

107. Gaede P, Vedel P, Larsen N, Jensen GV, Parving HH, Pedersen $\mathrm{O}$. Multifactorial intervention and cardiovascular disease in patients with type 2 diabetes. N Engl J Med. 2003 Jan;348(5):383-93.

108. American Diabetes Association Diabetes Care [Internet] 2020 Jan;43(Supplement 1):S98-S110. 